\title{
An Empirical Study on the Adoption of Online Household e-waste Collection Services in China
}

\author{
Shang Gao ${ }^{1}$, Jinjing $\mathrm{Shi}^{2}$, Hong Guo ${ }^{3}$, Jiawei Kuang ${ }^{2}$, Yibing $\mathrm{Xu}^{2}$ \\ ${ }^{1}$ Department of Computer and Information Science, \\ Norwegian University of Science and Technology \\ shanggao@idi.ntnu.no \\ ${ }^{2}$ School of Business Administration, \\ Zhongnan University of Economics and Law, Wuhan, China \\ arie11236@163.com, harveykuang.yali@gmail.com,xyb_mx2013@163.com \\ ${ }^{3}$ School of Business Administration, \\ Anhui University, Hefei, China \\ homekuo@gmail.com
}

\begin{abstract}
Online household e-waste collection services are emerging as new solutions to disposing household e-waste in China. This study aims to investigate the adoption of online household e-waste collection services in China. Based on the previous technology diffusion theories (e.g., TAM, UTAUT), a research model with six research hypotheses was proposed in this research. The research model was empirically tested with a sample of 203 users of online household e-waste collection services in China. The results indicated that five of the six research hypotheses were significantly supported. And the most significant determinant for the behavioral intention to use online household e-waste service was effort expectancy. However, facilitating condition did not have significant impact on users' behavior of using online household e-waste collection services.
\end{abstract}

Keywords: Adoption, UTAUT, online household e-waste collection services

\section{Introduction}

Today, electrical and electronic products become increasingly important in peoples' daily lives. However, it also produces a tremendous amount of e-waste in the mean time. To build a smart and sustainable city, the disposal of waste is a crucial aspect that should be taken into consideration. For example, E-waste has become a serious problem in China in terms of both quantity and toxicity, exacerbated by the development and advancement of electronic industry. A large amount of e-waste was generated in China due to the fast consumption rates of electrical and electronic products. E-waste was largely collected by the informal sector. According to the previous study (e.g., [22]), it was found that the majority of electrical and electronic products were often sold to peddlers. However, most peddlers tended to focus on waste fractions of the collected e-waste with which they can make a profit instead of focusing on raised environmental problems. 
With the rapid economic growth in China, consumers' demand for electrical and electronic products is booming simultaneously. We have witnessed exponential increase of the quantity of output of four major household appliances (e.g., TV) in the past two decades. For instance, the output of TVs has increased to 133.82 million units in 2014, from 33.70 million units in 1998. When these household appliances eventually reach the ends of their life circles, they will become obsolete and pose a potential threat to both natural environment and human health if they were not properly disposed. The recycling chain for e-waste is classified into three main subsequent steps: collection, sorting/dismantling and pre-processing (including sorting, dismantling and mechanical treatment) and end-processing [20]. Being the first step of the whole recycling chain, collection serves as a crucial process of ewaste recycling. Currently, there exist six major options for household e-waste disposal: second use, storage, discarding, disassembly, formal collection and informal collection [6]. Online household e-waste collecting and recycling platform is aiming to become a convenient way of collecting e-waste and to offer higher recycling price than official price notwithstanding. However, it seems that most Chinese electrical and electronic products consumers are not familiar with this platform.

Online household e-waste collection revolutionizes the traditional ways of collecting and disposing e-waste. It integrates information flows, logistics and capital flows, constructing a closer connection between e-waste sellers and recyclers, which facilitates the e-waste collecting process and ultimately improves the effectiveness and efficiency of the whole recycling chain for e-waste.

The objective of this research is to investigate consumers' behavior intention to use online household e-waste collection services in China. Based on previous technology diffusion theories (e.g., TAM[7], UTAUT[26]), a research model with six research hypotheses was proposed. And the research model was empirically tested using data collected from a survey of users of an online household e-waste collection service called Taolv365 in China.

The remainder of this paper is organized as follows. The related literature review is reviewed in Section 2. The research model and hypotheses are presented in section 3. In Section 4, an empirical study is carried out to examine the research model. This is followed by a discussion of the findings and limitation of the study in section 5 . Section 6 concludes this research work and points out directions for future research.

\section{Literature Review}

\subsection{Technology Diffusion Theories}

An important and long-standing research question in information systems research is how to accurately explain user adoption of information systems [8]. Several models have been developed to test the users' attitude and intention to adopt new technologies or information systems. These models include the Technology Acceptance Model (TAM) [7], Theory of Planned Behavior (TPB) [1], Innovation Diffusion Theory (IDT) [19], Unified Theory of Acceptance and Use of Technology (UTAUT) [26], and Mobile Services Acceptance Model (MSAM) [11, 12]. UTAUT 
was developed through a review and consolidation of the constructs of eight models (e.g., TAM, TRA[9], TPB, IDT) that earlier research had employed to explain IS usage behavior. Moreover, variables that influence users' behavioral intention employed in TAM3 [23] were classified into the following four types: individual differences, system characteristics, social influence and facilitating conditions [24].

Due to its unified perspective, although UTAUT has not been as widely used as TAM, partly resulting from its complexity and intricacy to test its applicability, it has gradually drawn researchers' attentions and has been recently applied to exploring user acceptance of mobile technologies and mobile devices (e.g., [4], [14, 17]). We built our research model based on UTAUT to assess the adoption of online household e-waste collection services in China.

\subsection{Research on e-waste collection services in China}

As the largest exporter of electrical and electronic products and importer of waste electrical and electronic products around the world, China plays a key role in the global life cycle of electronics [28]. Being concerned about the dispose of e-waste, many studies have been conducted during the last few decades.

Table 1. Literature review on e-waste collection system in China

\begin{tabular}{|c|c|c|}
\hline Literature & Research purpose & Findings \\
\hline $\begin{array}{l}\text { Streicher- } \\
\text { Porte, } \\
\text { Geering, } \\
2009 \text { [22] }\end{array}$ & $\begin{array}{l}\text { Analyze household data and } \\
\text { compares literature sources } \\
\text { about how Chinese } \\
\text { households dispose of } \\
\text { obsolete electrical and } \\
\text { electronic equipment. }\end{array}$ & $\begin{array}{l}\text { The findings indicated that the informal } \\
\text { collection sector of obsolete EEE in China } \\
\text { mainly in terms of door-to-door collection by } \\
\text { peddlers played a major role in the current } \\
\text { management of this waste stream. }\end{array}$ \\
\hline $\begin{array}{l}\text { Yu, } \\
\text { Williams, } \\
\text { Ju, \& Shao, } \\
2010 \text { [28] }\end{array}$ & $\begin{array}{l}\text { Review the existing } \\
\text { framework for e-waste } \\
\text { management in China } \\
\text { including regulatory } \\
\text { policies and pilot projects. }\end{array}$ & $\begin{array}{l}\text { Two alternate policies were proposed: } \\
\text { shared responsibility with deposit to } \\
\text { incentivize consumer participation and } \\
\text { integrating informal collection/reuse with } \\
\text { formal dismantling/recycling. }\end{array}$ \\
\hline $\begin{array}{l}\text { Chi, } \\
\text { Streicher- } \\
\text { Porte, } \\
\text { Wang, \& } \\
\text { Reuter, } \\
2011[5]\end{array}$ & $\begin{array}{l}\text { Gather information on } \\
\text { informal } \quad \text { e-waste } \\
\text { management, take a look at } \\
\text { its particular manifestations } \\
\text { in China }\end{array}$ & $\begin{array}{l}\text { The findings revealed the actual situation of } \\
\text { e-waste management in China. Moreover, it } \\
\text { indicated that the improvement of informal } \\
\text { recycling sector lied on dedicated efforts } \\
\text { from economic, technical and social aspects. }\end{array}$ \\
\hline $\begin{array}{l}\text { Chi, Wang, } \\
\& \text { Reuter, } \\
2014[6]\end{array}$ & $\begin{array}{l}\text { Investigate the collection } \\
\text { channels of e-waste and } \\
\text { household recycling } \\
\text { behaviors in Taizhou city of } \\
\text { China. }\end{array}$ & $\begin{array}{l}\text { The authors suggested that rather than } \\
\text { directly competing with the informal } \\
\text { collection sector, a better solution was to } \\
\text { harness its strengths and incorporate it into a } \\
\text { more accountable and regulated e-waste } \\
\text { collection system. }\end{array}$ \\
\hline
\end{tabular}

As shown in Table 1, previous studies have provided us with different aspects to understand the current situations of e-waste collection and recycling system in China, including the legislative policy, e-waste collection channels, household recycling 
behaviors, etc. However, they were mainly focusing on the traditional methods of ewaste dispose while neglecting online e-waste collection services.

This research aims to complement and extend existing studies on the adoption of ewaste collection services by focusing on the emerging channel of disposing e-waste: online household e-waste collection services. The online household e-waste collection services can be seen as information systems. Therefore, we would like to use the existing technology diffusion theories to examine the adoption of online household ewaste collection services in China.

\section{Research Model and Hypotheses}

A research model that identifies important factors that impact users' intention to use online household e-waste collection services was developed in this research. The proposed research model (see Figure 1) is a simplified version of UTAUT. We have developed the following six research hypotheses (labeled in Figure 1) based on the research model.

\section{Performance expectancy and Effort expectancy}

Performance expectancy is defined as the degree to which an individual believes that using the system will help him or her to attain gains in job performance [26]. It reflects user perception of performance improvement by using online household ewaste collection services such as convenience, fast response, and service effectiveness. The performance expectancy construct is the strongest predictor of behavioral intention and remains significant at all settings [26]. When users feel that online household e-waste collection services are useful and can bring them convenience to dispose their e-waste, their intention to use to the services are likely to be high.

Effort expectancy is defined as the degree of ease associated with the use of the system [26]. It reflects user perception of how difficult it is to use online household ewaste collection services. According to earlier research (e.g., [26]), effort expectancy positively affects performance expectancy. When users feel that online household ewaste collection services are easy to use and do not require much effort, they will have a high expectation toward acquiring the expected performance. Otherwise, their performance expectancy is likely to be low. Thus, we formulate the following research hypotheses:

H1: Effort expectancy has a positive influence on performance expectancy.

H2: Performance expectancy has a positive influence on users' behavioral intention of using online household e-waste collection services.

H3: Effort expectancy has a positive influence on users' behavioral intention of using online household e-waste collection services.

\section{Social Influence}

Social influence is similar to subjective norm of TRA and reflects the effect of environmental factors such as the opinions of a user's friends, relatives, and superiors on user behavior[15]. In addition, recommendation as well as word-of-mouth effect will also affect consumers' behavioral intention [10]. Thus, we formulate the following research hypothesis: 
H4: Social influence has a positive influence on users' behavioral intention of using online household e-waste collection services.

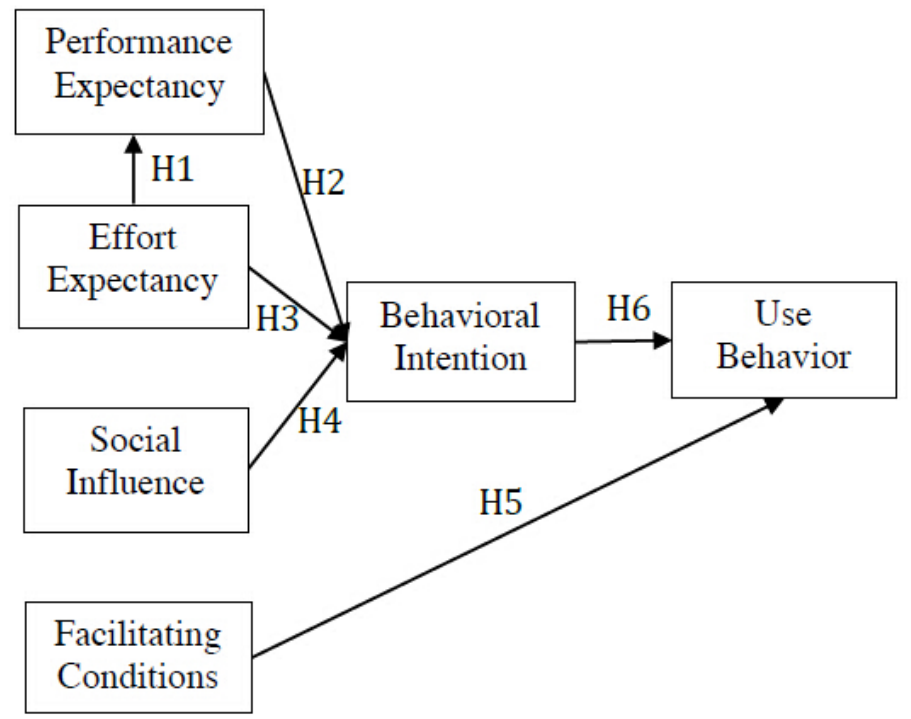

Figure 1. Research Model

\section{Facilitating Conditions}

Facilitating conditions are similar to perceived behavioral control of TPB and reflect the effect of a certain user's knowledge, ability, and resources [26]. Online household e-waste service is a rather new service for e-waste recycling, but similar to other e-commerce services. In order to use this service, users need some basic infrastructures like PC, smart phones, Internet, etc. In addition, users need to bear usage costs such as data service and logistics fees when using online household ewaste collection services. If users do not have these necessary devices as well as financial resources and operational skills, they are not likely to adopt or use online household e-waste collection services. Thus, we formulate the following research hypothesis:

H5: Facilitating conditions have a positive influence on users' behavior of using online household e-waste collection services.

\section{Behavior Intention}

Consistent with the underlying theory for all of the intention models [21], we expect that behavioral intention will have a significant positive influence on usage behavior [26]. If the intention of a certain user to use online household e-waste collection services is high, he or she will be more likely to use this service. Otherwise, the user is unlikely to adopt this service. Thus, we formulate the following research hypothesis:

H6: Behavioral intention has a positive influence on use behavior. 


\section{$4 \quad$ An Empirical Study with the Research Model}

In this empirical test, our research model was examined through the use online household e-waste collection service called Taolv365.

\subsection{The online household e-waste collection service: Taolv365}

Taolv365 aimed to build online household recycling system with Chinese characteristics. It is one of the first pioneers using the Internet as the basis for the reverse supply service platform. In addition, it has largest amount of registered users in China. Therefore, this website is a good case for instrument testing and identifying relevant implications for practitioners.

Based on the national environmental standards, Taolv365 gradually establishes the system of online household e-waste collection services to manage the chaotic ewaste collection market. Taolv365 also aimed to deal with some existing recycling problems (e.g., the lack of channels). Their ambition is to create an intelligent and green recycling system to collect e-waste in a more convenient and environmentalfriendly way.

Taolv365 provides the following three services to the users:

- Information service: Taolv365 can provide information to the clients in the following channels: call center, online messaging service, and the third platform collecting channels which can offer 7days/24hours help to users. Anyone who has e-waste can choose one of the channels for help.

- Price inquiry service: E-waste is classified on Taolv365. Users can easily get the price of their e-waste according to the standard classification system. It also provides SMS platform for immediate feedback, professional customer service so that users can timely grasp of recycling market and trends. Users can also donate their devices or electronics to charities via Taolv365.

- The transaction channel service: The website integrates recycling industry buyers through formal channels. The buyers bid online, commit the transaction volume and shipments, and classify the standards carefully so as to achieve the optimal price. As long as submitting the order, the service can get the real-time tracking of the logistics, trading and payment situations.

\subsection{Instrument Development}

The validated instrument measures from previous research were used as the foundation to create the instrument for this study. Previous studies were reviewed to ensure that a comprehensive list of measures were included. In order to ensure that the instrument better fit this empirical study, some minor words changes were made to ensure easy interpretation and comprehension of the questions. All the items were adopted from prior studies [26] and modified to fit the domain of online household e- 
waste collection services. As a result, 17 measurement items ${ }^{1}$ were included in the questionnaires. In addition, a seven-point Likert scale, with 1 being the negative end of the scale (strongly disagree) and 7 being the positive end of the scale (strongly agree), was used to examine participants' responses to all items in the survey.

\subsection{Samples}

The data for this study was collected through paper-based questionnaires from 20th April to 30th April 2015 in the biggest city in the central China. People were asked to participate in the survey voluntarily. Firstly, we explained who we were, what they were supposed to do during our survey, and the purpose of the survey. The participants were also informed that the results would be reported only in aggregate and their anonymity would be assured. After participants experienced the online household e-waste collection service provided by Taolv365, they were asked to complete the questionnaires and submitted them to us. 210 completed questionnaires were collected, among which 203 of them were valid questionnaires (i.e., valid respondent rate $96.7 \%$ ). Among the participants, 86 of the participants were male, and 117 were female. In terms of age, 120 participants were 25 years old and under 25 years old, while 83 participants were over 25 years old.

\subsection{Descriptive Results}

Some key findings from the descriptive results are summarized in this section. The means for each of the items in the survey are presented in Table 2 . The mean value for the measurement value PE1 is 5.30. 145 of the 203 respondents $(71.43 \%$ ) agreed that the service of online household e-waste collection was useful. In the same time, 144 respondents felt that online household e-waste collection service improved both their efficiency and convenience of handling e-waste.

According to the results, most respondents thought that it would be easy for them to use online household e-waste collection services. 132 respondents indicated that it is easy for them to learn how to use online household e-waste collection services. Moreover, gender differences had an obvious effect on peoples' reaction towards social influence. Men were more likely to be affected by someone who were important to or had influence on them than women. Similarly, effort expectancy has a more significant likelihood to result in peoples' behavioral intention among men than women.

Item FC1 has the highest mean value in the construct facilitating conditions. Most respondents indicated that they had the necessary resources to use online household ewaste collection services. Furthermore, many of them thought that they had the necessary knowledge to use online household e-waste collection services.

Furthermore, many respondents gave us a neutral response when we were asking the question on their frequency to use online household e-waste collection services to deal with their household appliances or electronic devices. This means that there is still a huge business market for online household e-waste collection services in China.

\footnotetext{
1 The survey items are available at this link: http://www.idi.ntnu.no/ shanggao/ewaste.html
} 
Table 2. Means, Factor loadings, composite reliability, and AVE for each Item

\begin{tabular}{|c|c|c|c|c|c|c|}
\hline Construct & Item & Mean & Factor loading & $\begin{array}{l}\text { Composite } \\
\text { reliability }\end{array}$ & AVE & $\begin{array}{l}\text { Cronbach's } \\
\text { Alpha }\end{array}$ \\
\hline \multirow{3}{*}{$\begin{array}{l}\text { Performance } \\
\text { expectancy }\end{array}$} & PE1 & 5.30 & 0.850 & \multirow[t]{3}{*}{0.927} & \multirow[t]{3}{*}{0.810} & \multirow[t]{3}{*}{0.882} \\
\hline & PE2 & 5.16 & 0.925 & & & \\
\hline & PE3 & 5.26 & 0.923 & & & \\
\hline \multirow{4}{*}{$\begin{array}{l}\text { Effort } \\
\text { expectancy }\end{array}$} & EE1 & 4.68 & 0.932 & \multirow[t]{4}{*}{0.950} & \multirow[t]{4}{*}{0.827} & \multirow[t]{4}{*}{0.930} \\
\hline & EE2 & 4.58 & 0.919 & & & \\
\hline & EE3 & 4.98 & 0.898 & & & \\
\hline & EE4 & 4.65 & 0.888 & & & \\
\hline \multirow{2}{*}{$\begin{array}{l}\text { Social } \\
\text { influence }\end{array}$} & SI1 & 4.51 & 0.965 & \multirow[t]{2}{*}{0.968} & \multirow[t]{2}{*}{0.937} & \multirow[t]{2}{*}{0.933} \\
\hline & SI2 & 4.47 & 0.917 & & & \\
\hline \multirow{3}{*}{$\begin{array}{l}\text { Facilitating } \\
\text { conditions }\end{array}$} & FC1 & 5.17 & 0.867 & \multirow{3}{*}{0.913} & \multirow{3}{*}{0.778} & \multirow{3}{*}{0.867} \\
\hline & FC2 & 5.15 & 0.877 & & & \\
\hline & FC3 & 4.70 & 0.901 & & & \\
\hline \multirow{3}{*}{$\begin{array}{l}\text { Behavioral } \\
\text { intention }\end{array}$} & BI1 & 4.88 & 0.939 & \multirow{3}{*}{0.946} & \multirow{3}{*}{0.854} & \multirow{3}{*}{0.914} \\
\hline & BI2 & 4.86 & 0.918 & & & \\
\hline & $\mathrm{BI} 3$ & 4.72 & 0.914 & & & \\
\hline \multirow[t]{2}{*}{ Use behavior } & UB1 & 4.02 & 0.974 & \multirow[t]{2}{*}{0.973} & \multirow[t]{2}{*}{0.947} & \multirow[t]{2}{*}{0.944} \\
\hline & UB2 & 4.11 & 0.973 & & & \\
\hline
\end{tabular}

Table 3. Discriminant Validity

\begin{tabular}{ccccccc}
\hline Variables & BI & EE & FC & PE & SI & UB \\
\hline BI & 0.924 & & & & & \\
EE & 0.755 & 0.909 & & & & \\
FC & 0.825 & 0.803 & 0.882 & & & \\
PE & 0.730 & 0.732 & 0.713 & 0.900 & & \\
SI & 0.760 & 0.714 & 0.667 & 0.649 & 0.968 & \\
UB & 0.670 & 0.593 & 0.538 & 0.521 & 0.693 & 0.973 \\
\hline
\end{tabular}

Note: Diagonals represent the average variance extracted, while the other matrix entries represent the squared correlations.

\subsection{Measurement Model}

The quality of the measurement model is determined by (1). Content validity, (2). Construct reliability and (3). Discriminant validity [2]. To ensure the content validity of our constructs, a pretest with 6 researchers in the field of information systems was carried out in March 2015. And we found that the questionnaire was well understood by all the researchers.

To further test the reliability and validity of each construct in the research model, the Internal Consistency of Reliability (ICR) of each construct was tested with Cronbach's Alpha coefficient. As a result, the Cronbach's Alpha values range from 0.867 to 0.944 . A score of 0.7 is marked as an acceptable reliability coefficient for Cronbach's Alpha [18]. All the constructs in the research model were above 0.70 . Consequently, the scales were deemed acceptable to continue.

Convergent validity was assessed through composite reliability (CR) and the average variance extracted (AVE). Bagozzi and Yi [3] proposed the following three measurement criteria: factor loadings for all items should exceed 0.5 , the CR should exceed 0.7, and the AVE of each construct should exceed 0.5. As shown in Table 3, all constructs were in acceptable ranges. 


\subsection{Structural Model and Hypotheses Testing}

The structural model was tested using SmartPLS. Table 4 presents the path coefficients, which are standardized regression coefficients. Five (H1, H2, H3, H4, H6) of the six research hypotheses were significantly supported. According to the results, performance expectancy, effort expectancy and social influence were found to have a statistically significant effect on users' behavior intention to use online household e-waste collection services, while facilitating condition did not have significant impact on users' behavior of using online household e-waste collection services.

The $\mathrm{R}^{2}$ ( $\mathrm{R}$ square) denotes to coefficient of determination. It provides a measure of how well future outcomes are likely to be predicted by the model, the amount of variability of a given construct. In our analysis, the $\mathrm{R}^{2}$ coefficient of determination is a statistical measure of how well the regression coefficients approximate the real data point. According to the result, $70.4 \%$ of the variance of behavior intention can be explained by the research model.

Table 4. Test of hypotheses based on path coefficient

\begin{tabular}{lcc}
\hline \multicolumn{1}{c}{ Hypothesis } & $\begin{array}{c}\text { Path } \\
\text { Coefficient }\end{array}$ & $\begin{array}{c}\text { Hypothesis } \\
\text { Result }\end{array}$ \\
\hline H1.Effort expectancy to performance expectancy & $0.732 * * *$ & Supported \\
H2.Performance expectancy to behavior intention & $0.279 * *$ & Supported \\
H3.Effort expectancy to behavior intention & $0.281 * *$ & Supported \\
H4.Social influence to behavior intention & $0.379 * *$ & Supported \\
H5.Facilitating conditions to behavior intention & -0.044 & Not supported \\
H6.Behavior intention to use behavior & $0.706 * * *$ & Supported \\
\hline \multicolumn{2}{c}{$* 0.05 ; * \mathrm{p}<0.01 ; * * * \mathrm{p}<0.001$} &
\end{tabular}

\section{Discussion}

In this research, we studied the adoption of online household e-waste collection services in China. From the theoretical perspective, this research contributed to the literature on the adoption of new technologies (i.e., online e-waste collection services) in China by building upon previous technology diffusion theories. To our best knowledge, most previous studies were mainly focusing on the traditional channels of household collection as well as the conflicts between formal and informal e-waste recycling systems (e.g., [6, 22]). This research is one of the first studies to examine users' adoption of online household e-waste collection services in China. From a practical perspective, it offered some insights to the use and adoption of online household e-waste collection services in China.

Since effort expectancy has an indirect effect on users' behavioral intention through performance expectancy, the total effect of effort expectancy on behavioral intention is $0.281+0.732 * 0.279=0.485$. Therefore, the most important determinant for the behavioral intention to use online household e-waste service was effort expectancy, while social influence and performance expectancy were ranked as second and third respectively. As to the significant impact of social influence on users' behavior intention, one possible explanation is that Chinese consumers are considered to be 
more concerned about their social images. Moreover, the effect of word-of-mouth is an important influencer in China [27]. In addition, effort expectancy has an significant positive influence on performance expectancy, which is consistent with previous research findings [26]. However, facilitating conditions is not proved to be the determinant for the use behavior. This can be partially attributed to the fact that most participants in this study were between 15 to 25 years old. They were quite skillful at using online services and unlikely to ask for help from their fellows. This had been further confirmed in the follow-up interview session. Some participants also indicated that online household e-waste collection services were easy to use so that they did not need help from others. Thus, facilitating conditions did not have a significant positive influence on use behavior. This is also consistent with the previous findings (e.g., [25] [13]).

When promoting the online household e-waste collection services, practitioners could make advantage of social influence, such as celebrity worship and the effect of word-of-mouth, especially in countries like China. Moreover, most participants believed that online household e-waste collection services improve the efficiency to deal with household e-waste. It was also interesting to note that people with different gender and age groups responded differently to social influence. The results indicated that men were much more likely to be affected by someone who were important or have influence on them than women.

However, we were also aware of some limitations. Firstly, we only tested the research model and research hypotheses with samples from one province in China. This sample might not be fully representative of the entire population in China. Secondly, all the data were collected using self-reported scales in the research. This may lead to some caution because common method variance may account for some of the results that has been cited as one of the stronger criticisms of tests of theories with TAM and TAM-extended research [16]. However, our data analysis with convergent and discriminant validity does not support the presence of a strong common methods bias. Last but not least, the services provided by Taolv365 may not represent all the online household e-waste collection services.

\section{Conclusion and Future Research}

This research was designed to explore users' adoption of online household e-waste collection services in China. A research model with six research hypotheses was proposed. The results indicated that five of the six research hypotheses were significantly supported. And the most significant determinant for the behavioral intention to use online household e-waste service was effort expectancy. However, facilitating condition did not have a significant positive impact on users' behavior of using online household e-waste collection services.

Continuing with this stream of research, we plan to examine some additional constructs' (e.g., trust) influence on the adoption of online household e-waste collection services. Future research is also needed to empirically verify the research model with larger samples across China. 


\section{References}

1. Ajzen, I.: The theory of planned behavior. Organizational Behavior and Human Decision Processes. 50 (2), 179-211 (1991)

2. Bagozzi, R.P.: The role of measurement in theory construction and hypothesis testing: toward a holistic model. In: Ferrell, O.C., Brown, S.W. and Lamb, C.W. (eds.) Conceptual and theoretical developments in marketing, 15-32 (1979)

3. Bagozzi, R.P. and Yi, Y.: Specification, evaluation, and interpretation of structural equation models. Journal of the Academy of Marketing Science. 40 (1), 8-34 (2012)

4. Carlsson, C., Carlsson, J., Hyvonen, K., et al. Adoption of Mobile Devices/Services Searching for Answers with the UTAUT Proceedings of the 39th Annual Hawaii International Conference on System Sciences - Volume 06, IEEE Computer Society, (2006)

5. Chi, X., Streicher-Porte, M., Wang, M.Y., et al.: Informal electronic waste recycling: a sector review with special focus on China. Waste Management. 31 (4), 731-742 (2011)

6. Chi, X., Wang, M.Y. and Reuter, M.A.: E-waste collection channels and household recycling behaviors in Taizhou of China. Journal of Cleaner Production. 80, 87-95 (2014)

7. Davis, F.D.: Perceived usefulness, perceived ease of use and user acceptance of information technology. MIS Quarterly. 13 (3), 319-340 (1989)

8. DeLone, W. and McLean, E.: Information Systems Success: The Quest for the Dependent Variable. Information Systems Research. 3 (1) (1992)

9. Fishbein, M. and Ajzen, I.: Belief, Attitude, Intention and Behavior: An Introduction to Theory and Research. Addison-Wesley (1975)

10. Fitzsimons, G.J. and Lehmann, D.R.: Reactance to recommendations: When unsolicited advice yields contrary responses. Marketing Science. 23 (1), 82-94 (2004)

11. Gao, S., Krogstie, J. and Gransæther, P.A.: Mobile Services Acceptance Model. In: the proceedings of International Conference on Convergence and Hybrid Information Technology. IEEE Computer Society (2008)

12. Gao, S., Krogstie, J. and Siau, K.: Adoption of mobile information services: An empirical study. Mobile Information Systems. 10 (2), 147-171 (2014)

13. Gao, S., Krogstie, J. and Yang, Y.: Differences in the Adoption of Smartphones Between Middle Aged Adults and Older Adults in China. In: Zhou, J. and Salvendy, G. (eds.) Human Aspects of IT for the Aged Population. Design for Aging. 9193, 451-462. Springer Berlin Heidelberg (2015)

14. Gao, S., Yang, Y. and Krogstie, J.: The Adoption of Smartphones Among Older Adults in China In: Liu, K., Nakata, K., Li, W., et al. (eds.) Information and Knowledge Management in Complex Systems. 449. Springer Berlin Heidelberg (2015)

15. López-Nicolás, C., Molina-Castillo, F.J. and Bouwman, H.: An assessment of advanced mobile services acceptance: Contributions from TAM and diffusion theory models. Information \& Management. 45 (6), 359-364 (2008)

16. Malhotra, N.K., Kim, S.S. and Patil, A.: Common method variance in IS research: A comparison of alternative approaches and a reanalysis of past research. Management Science. 52 (12), 1865-1883 (2006)

17. Park, J., Yang, S. and Lehto, X.: Adoption of mobile technologies for Chinese consumers. Journal of Electronic Commerce Research. 8 (3), 196-206 (2007)

18. Robinson, J.P., Shaver, P.R. and Wrightsman, L.S.: Criteria for scale selections and evaluation. Academic Press, San Diego, CA (1991)

19. Rogers, E.M.: The diffusion of innovations. Free Press, New York (1995) 
20. Schluep, M., Hagelueken, C., Kuehr, R., et al.: Sustainable Innovation and Technology Transfer Industrial Sector Studies: Recycling-from E-waste to Resources. United Nations Environment Programme \& United Nations University, Bonn, Germany (2009)

21. Sheppard, B.H., Hartwick, J. and Warshaw, P.R.: The theory of reasoned action: A meta-analysis of past research with recommendations for modifications and future research. Journal of consumer research, 325-343 (1988)

22. Streicher-Porte, M. and Geering, A.-C.: Opportunities and threats of current e-waste collection system in China: a case study from Taizhou with a focus on refrigerators, washing machines, and televisions. Environmental Engineering Science. 27 (1), 2936 (2010)

23. Venkatesh, V. and Bala, H.: TAM 3: Advancing the technology acceptance model with a focus on interventions. Manuscript in preparation. Retrieved from http://www.vvenkatesh.com/IT/organizations/Theoretical_Models.asp (2013)

24. Venkatesh, V. and Bala, H.: Technology acceptance model 3 and a research agenda on interventions. Decision sciences. 39 (2), 273-315 (2008)

25. Venkatesh, V. and Davis, F.D.: A Theoretical Extension of the Technology Acceptance Model: Four Longitudinal Field Studies. Manage. Sci. 46 (2), 186-204 (2000)

26. Venkatesh, V., Morris, M.G., Davis, G.B., et al.: User acceptance of information technology: Toward a unified view. MIS quarterly, 425-478 (2003)

27. Wiedemann, D.G., Haunstetter, T. and Pousttchi, K.: Analyzing the basic elements of mobile viral marketing-an empirical study. In: Mobile Business, 2008. ICMB'08. 7th International Conference on, 75-85. IEEE (2008)

28. Yu, J., Williams, E., Ju, M., et al.: Managing e-waste in China: Policies, pilot projects and alternative approaches. Resources, Conservation and Recycling. 54 (11), 991-999 (2010) 